\title{
Relationship between habitat distribution, growth rate, and plasticity in congeneric larval dragonflies
}

\author{
S.J. McCauley
}

\begin{abstract}
The relationship between habitat distribution, growth rate, and plasticity was examined in the larvae of three species of dragonfly in the genus Libellula L., 1758. Growth rates were compared under three conditions: in the absence of predation risk, in the presence of sunfish (Lepomis macrochirus Rafinesque, 1819; Pisciformes: Centrachidae), and in the presence of invertebrate predators. I assessed how the habitat distributions of the three species of dragonfly, specifically how commonly they occur with fish, were related to growth rates and to the level of growth plasticity under different levels of perceived predation risk. There was a negative relationship between growth rate and the frequency with which species coexist with sunfish. Growth-rate plasticity was limited and does not appear to be important in determining the ability of species to coexist with alternative top predator types. Only one species exhibited growthrate plasticity, decreasing growth in response to the predator with which it most commonly coexists but not to the species which poses the greatest predation risk. A comparison of growth rates and activity levels in the presence and absence of these predators suggests that growth and activity level parallel each other in these species.
\end{abstract}

Résumé : La relation entre la répartition de l'habitat, le taux de croissance et la plasticité a été étudiée chez des larves de trois espèces de libellules du genre Libellula L., 1758. La comparaison des taux de croissance s'est faite sous trois conditions, soit en absence de risque de prédation, en présence de crapets (Lepomis macrochirus Rafinesque, 1819; Pisciformes : Centrachidae) et en présence d'invertébrés prédateurs. L'objectif était d'évaluer comment les répartitions des habitats larvaires des trois espèces, et en particulier la fréquence de cohabitation avec les poissons, sont reliées aux taux de croissance et au niveau de plasticité de la croissance sous divers niveaux de perception de risques de prédation. Il y a une relation négative entre le taux de croissance et la fréquence de coexistence des espèces avec les crapets. La plasticité du taux de croissance est limitée et ne semble pas être d'importance pour déterminer la capacité des espèces à cohabiter avec les divers types de prédateurs supérieurs. Une seule espèce possède une plasticité du taux de croissance : elle diminue sa croissance en réaction au prédateur avec lequel elle cohabite le plus communément, mais non à l'espèce qui pose le plus grand risque de prédation. Une comparaison des taux de croissance et des niveaux d'activité en présence de prédateurs et en leur absence laisse croire que la croissance et le niveau d'activité vont de pair chez ces espèces.

[Traduit par la Rédaction]

\section{Introduction}

Species' growth rates are often subject to opposing selection pressures (Arendt 1997), and the resolution of trade-offs in response to these selection pressures may affect the relative performance of species across habitat gradients or reflect exposure to alternative selection pressures encountered across these distributions. Growth rate is subject to selection because body size, the ultimate result of growth, is posi-

Received 15 February 2005. Accepted 21 July 2005.

Published on the NRC Research Press Web site at http://cjz.nrc.ca on 15 September 2005.

S.J. McCauley. Department of Ecology and Evolutionary Biology, University of Michigan, 830 North University Avenue, Ann Arbor, MI 48109-1048 USA (e-mail: mccaule@umich.edu). tively associated with many aspects of fitness in animals (Clutton-Brock 1988; Roff 1992; Stearns 1992), including insects (Thornhill and Alcock 1983; Honek 1993; odonates: Sokolovska et al. 2000). High growth rates, however, may also have physiological and developmental costs (Arendt 1997) and increase the risk of mortality from predators (reviewed in Gotthard 2001). This trade-off between predation risk and growth rate can be mediated by foraging rate, which increases resource uptake to fuel growth but also increases exposure to predators (Werner and Anholt 1993). The differential resolution of this trade-off can play an important role in determining the distribution of species across habitat gradients associated with transitions in the top predator community.

A top predator transition is common in aquatic systems, where fish dominate in more permanent habitats and invertebrates dominate in less permanent sites (Wellborn et al. 
1996). For odonate species that segregate across this transition, those species associated with habitats in which fish are the top predators are typically less active than species which occur in habitats where invertebrates are top predators (McPeek 2004 and references therein). Lower activity levels are associated with lower risk of mortality from fish but may have costs in reduced growth rates leading to longer developmental periods or smaller body sizes at emergence. Consequently, species that commonly use fish habitats are expected to have lower growth rates than species that primarily co-occur with invertebrate top predators. Species may also, however, coexist with multiple top predator types. Plasticity is expected to be advantageous for organisms that must cope with environmental variability (Schlichting and Pigliucci 1998). Therefore, resolving the trade-offs associated with each end of the habitat spectrum may favor plasticity in both activity levels and growth rates in species with generalist habitat distributions.

This study examined the relationship between species' distributions, larval growth rates, and growth-rate plasticity in three congeneric dragonflies (Odonata: Anisoptera: Libellula L., 1758). Larval growth rates and the degree of growth plasticity were measured in the presence and absence of predators common in different portions of the habitat gradient. I predicted that there would be a negative relationship between the frequency with which species are found in highrisk predator environments and their intrinsic growth rates. I also predicted that species which encounter multiple top predator types across their distribution would exhibit greater levels of plasticity than species with restricted distributions. Finally, I examined how growth was allocated to the major body segments, thorax and abdomen, across species and predator treatments. The size of the larval thorax is significantly correlated with the size of the thorax in the adult at emergence (McCauley 2005), making these allocation patterns of interest for the effects of growth patterns across this life-history transition.

\section{Methods}

\section{Study system}

The three Libellula species used in this study have similar developmental periods (each has an approximately 10-month aquatic larval stage), but differ in their distributional breadths with respect to the top predator community. Lentic habitats in southeastern Michigan include two common top predator environments: those dominated by sunfish (Pisciformes: Centrachidae) and those in which large invertebrates are the top predator (principally larvae of the aeshnid dragonfly Anax junius (Drury, 1773); hereinafter simply Anax). Two species examined in this study (Libellula pulchella Drury, 1773 and Libellula luctuosa Burmeister, 1839) occur with both top predator types, but differ in which habitats they are most common (Fig. 1). Libellula pulchella is principally associated with Anax habitats, while L. luctuosa is primarily associated with sunfish habitats. The third species (Libellula incesta Hagen, 1861) is restricted to sunfish lakes (Fig. 1).

Sunfish and Anax pose different levels of risk to prey species. Sunfish have higher predation rates on Libellula and other libellulid dragonfly larvae than Anax (McCauley,
Fig. 1. The distributions of three species of Libellula across habitats with alternative top predators. Bars represent the proportional occurrence of species in sites of each top predator type, which was calculated as the number of sites of each top predator type where a species was collected divided by the total number of sites in which the species was collected in a survey of 57 lakes and ponds in southeastern Michigan (data in McCauley 2005).

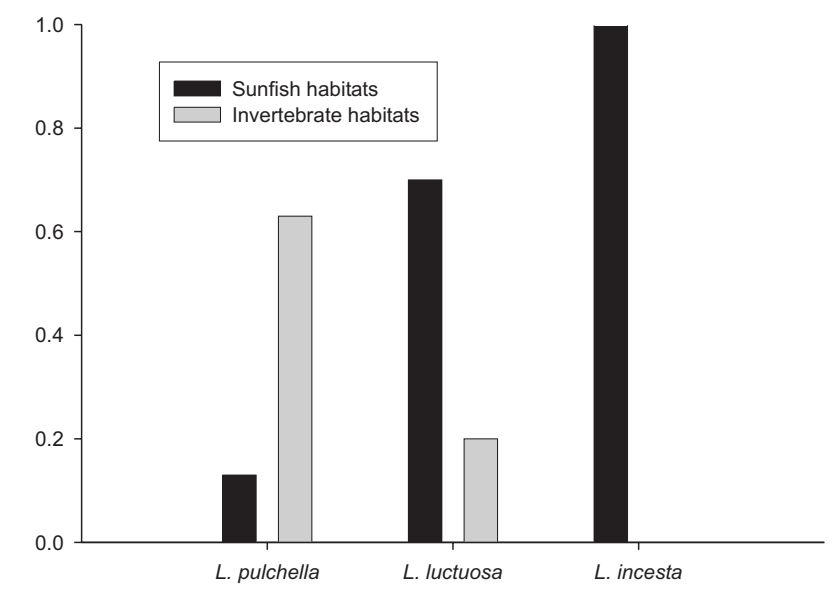

2005). The level of predation risk in Anax habitats varies over the ontogeny of the Anax population. Larval Anax populations within habitats can be strongly synchronized (personal observation) and early-instar Anax that have colonized ponds in spring pose little risk to Libellula larvae that have over-wintered, because of the size relationship between the two species. During the Anax flight season, Anax larvae may be entirely absent from these ponds (S.J. McCauley, unpublished data). These factors result in a high degree of temporal variability in the abundance of Anax and the level of threat they pose within these habitats.

\section{Growth rate experiment}

Larvae were collected from ponds on the University of Michigan's E.S. George Reserve and the surrounding Pinckney recreation area $\left(42^{\circ} 28^{\prime} \mathrm{N}, 84^{\circ} 00^{\prime} \mathrm{W}\right)$ in southeastern Michigan. Collection sites included both sunfish and Anax top predator environments, and species were collected from sites that represent the mix of habitats into which they naturally recruit. Species were preliminarily identified based on characteristics that differentiate species co-occurring in these sites. Definitive species-level identification of larvae requires examination of the interior mouthparts, a process that may negatively and permanently affect feeding behavior. Consequently, final species-level identifications were made after larvae were preserved individually at the end of the experiment.

Larval growth rates were compared in three treatments: (1) no predator, (2) nonlethal Anax junius, and (3) nonlethal bluegill (Lepomis macrochirus Rafinesque, 1819). The experiment was a split-plot design with species replicates occupying the same tanks. There were 11 replicates of each treatment. Containers for replicates were aquaria $(25 \mathrm{~cm} \times$ $50 \mathrm{~cm} \times 27 \mathrm{~cm}$ ) filled with well water. Each replicate housed nine Libellula larvae, three from each species. Larvae were held individually in $470-\mathrm{mL}$ clear plastic cups. The bottom 
of each cup was lined with gravel, which in conjunction with a small piece of screening placed in each cup provided larvae with both structure and a substrate to use for movement throughout the cup. Gravel also weighted cups to the bottom of the aquaria. Cups were capped with fine screening that separated the contents of the cup from the rest of the aquaria. Predators occupied the open portion of the aquaria. Libellula species are benthic, and the eyes of larvae are oriented towards the top of the head. Therefore, having cups on the bottom of the tank and predators occupying the open portion above was assumed to provide appropriate visual cues indicating the presence of predators. Aquaria were separated with solid plastic barriers to prevent the visual detection of predators in other replicates.

In addition to visual cues, larvae were exposed to chemical cues indicating the presence of predators. Twice per week, predators were fed two larval Leucorrhinia intacta (Hagen, 1861), a common libellulid dragonfly that co-occurs with all three species of Libellula. Consumption of $L$. intacta larvae by predators was expected to generate chemical cues indicating the presence of predators feeding on dragonfly larvae (e.g., Chivers et al. 1996). Aquaria were illuminated by fluorescent bulbs suspended above them on an $11 \mathrm{~h}$ light : $13 \mathrm{~h}$ dark cycle.

Libellula larvae were fed twice per week. Cups were removed from tanks and $5 \mathrm{~mL}$ of a freshly collected and concentrated zooplankton mix (principally daphniids and copepods) was added to each cup and then cups were recapped and replaced in the tank. Zooplankton were collected from cultures without predators so that there was no inadvertent exposure to chemical predator cues. This feeding schedule allowed larvae to feed ad libitum, indicated by the presence of small numbers of zooplankton in cups throughout the interfeeding interval. Exact numbers of zooplankton received by larvae varied across feeding sessions, but a larva received a range of 30-50 zooplankton per feeding and larvae all received equivalent amounts within a feeding session. Larvae were not fed for 6-8 days prior to ending the experiment to minimize differences resulting from recent feeding.

Larvae were measured prior to putting them in the experiment and at the end of the experiment. Head width, an integrative measure of odonate size (Benke 1970; Corbet 1999), was measured with vernier calipers (accuracy $\pm 0.01 \mathrm{~mm}$ ) on all larvae. Larvae were allowed to grow for between 43 and 45 days. After the final measurement, larvae were preserved individually and identified to species. Thorax length and abdomen length were measured on preserved larvae to assess the relative allocation to different body segments across species and treatments.

The relationship between activity level and growth rate was examined by combining growth rates measured in this experiment and mean activity rates. In a separate experiment, activity levels were measured for each Libellula species in three conditions: the absence of predators, in the presence of caged bluegill, and in the presence of caged Anax (details in McCauley 2005). I used the mean number of moves per hour (square-root transformed) for each species by predator combination and plotted the growth rate observed in this study against the activity level observed in the nonlethal presence of the same predator in the behavioral study (Fig. 2). These results are discussed qualitatively.
Fig. 2. Relationship between activity level and growth rate (based on head width measurements) in three species of Libellula. Each point represents the larval movement rate and growth rate in one of three predator treatments: no predator (squares), nonlethal Anax junius (circles), or nonlethal bluegill (triangles). Species are indicated as follows: L. pulchella (black), L. incesta (light gray), L. luctuosa (dark gray).

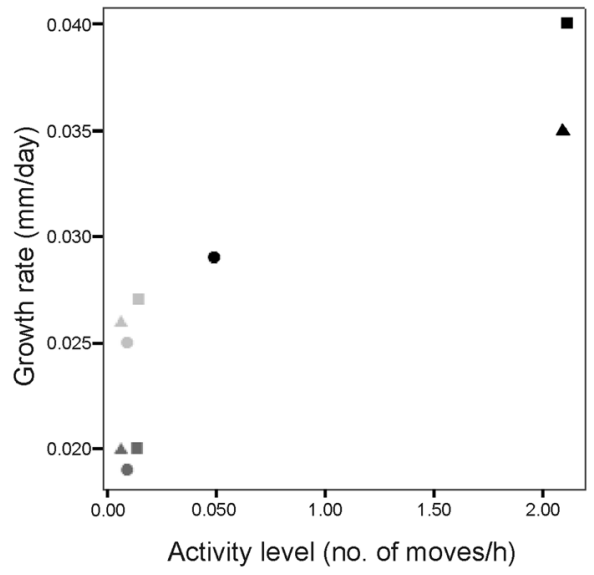

\section{Data analysis}

Growth increment was measured for each larva by subtracting the initial head width from the final head width. This variable was $\ln (x+1)$ transformed and then divided by the number of days a larva was in the trial to calculate growth rate. Relative allocation to the thorax was measured as the ratio of thorax length to body length (= thorax length + abdomen length). Two separate two-way, linear mixedmodel ANOVAs were used to assess the effect of predator treatment and species on growth rate and the thorax to body length ratio over shared tank effects. Growth rate and thorax to body length ratio were used as response variables. Predator and species were fixed effects, while tank was treated as a random factor. Pairwise comparisons of main effects were based on estimated marginal means with a Bonferroni adjustment for multiple comparisons. Within species plasticity in growth rate was assessed using three separate one-way, linear mixed-model ANOVAs, one for each species, to compare growth rates across treatments over shared tank effects. Growth rate was used as a response variable, while tank was treated as a random factor. All analyses were done in SPSS ${ }^{\circledR}$ version 11.5 (SPSS Inc. 2002).

\section{Results}

Mortality was low and equivalent across treatments. Of the 296 larvae used in the experiment, 16 died during the trial. There was no pattern of differential mortality between species. Of the larvae that survived, 13 had been misidentified prior to being used in the trial. Five of these individuals were species not examined in the experiment. These individuals were dropped from the analysis. Individuals that had been misidentified, but were species used in this experiment, were included in analyses after assigning the correct species identifications.

Species differed in growth rate $\left(F_{[2,265]}=26.93, p<\right.$ 0.001). Libellula incesta grew more slowly than L. luctuosa 
Fig. 3. Growth rates of three species of Libellula in three predator treatments. Data are means + SE. Species are indicated as follows: L. pulchella (black), L. incesta (light gray), L. luctuosa (dark gray).

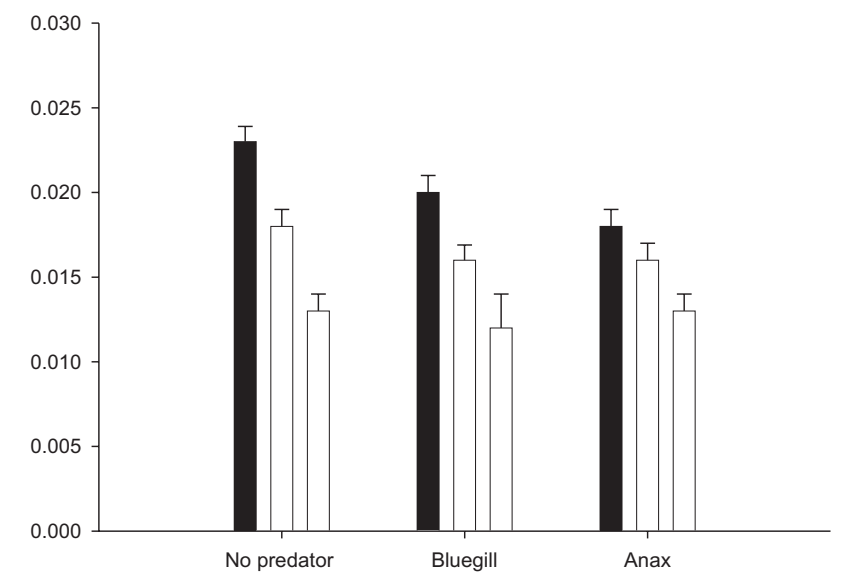

( $p=0.001)$ and L. pulchella $(p<0.001)$, while L. luctuosa grew more slowly than L. pulchella $(p=0.001)$ (Fig. 3). There was no effect of predator on growth rate $\left(F_{[2,265]}=\right.$ 2.65, $p=0.073)$ and no predator $\times$ species interaction $\left(F_{[4,265]}=0.76, p=0.554\right)$.

Libellula pulchella was the only species to exhibit significant plasticity in growth rate $\left(F_{[2,94]}=3.80, p=0.026\right)$. The growth rate of $L$. pulchella was lower in the presence of Anax than in the no predator treatment $(p=0.019)$, but there were no differences between growth rates in other treatments (all $p>0.2)$. Neither L. luctuosa $\left(F_{[2,93]}=0.62, p=0.538\right)$ nor $L$. incesta $\left(F_{[2,78]}=0.29, p=0.747\right)$ differed in growth rate across predator treatments.

Species differed in their thorax to body length ratio $\left(F_{[2,265]}=7.04, p=0.001\right)$, and this ratio differed across predator treatments $\left(F_{[2,265]}=4.54, p=0.012\right)$. Species' responses to predators were similar and there was no species $\times$ predator interaction $\left(F_{[4,265]}=0.149, p=0.966\right.$; Fig. 4). Libellula luctuosa had a larger thorax to body length ratio than L. pulchella $(p=0.022)$ and L. incesta $(p=0.001)$. Libellula incesta and L. pulchella did not differ in the proportional size of the thorax $(p=0.935)$. All species had a higher thorax to body length ratio in the bluegill treatment than in the no predator treatment $(p=0.009)$. There were no differences in the thorax to body length ratio between the bluegill and Anax treatments $(p=0.629)$ and the Anax and no predator treatments $(p=0.235)$ (Fig. 4).

\section{Discussion}

This study showed a negative relationship between growth rate and the extent to which species are associated with sunfish habitats. The species restricted to sunfish lakes (L. incesta) had the lowest growth rate under all conditions. Two species,L. luctuosa and L. pulchella, occur with both types of top predators, but L. luctuosa occurs more commonly with sunfish and had a lower growth rate than L. pulchella, which is most frequently found in habitats where Anax is the top predator. All three species of Libellula have lower survivorships with bluegill than with Anax (McCauley 2005), suggesting that their predation risk is
Fig. 4. Proportional allocation to body segments in three species of Libellula plotted as the ratios of larval thorax length to body length. Data are means + SE. Species are indicated as follows: L. pulchella (black), L. incesta (light gray), L. luctuosa (dark gray).

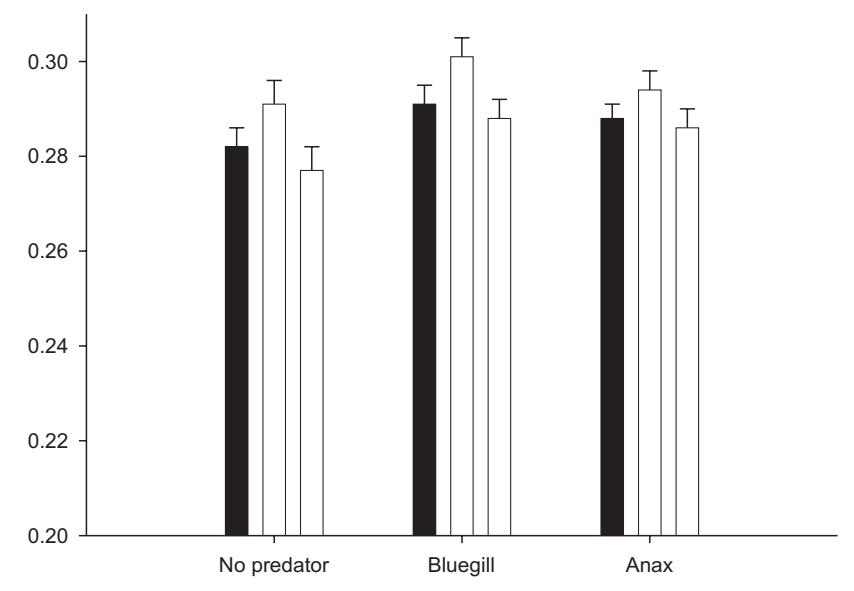

greater in habitats with bluegill than in habitats with Anax. These results were comparable to findings in other systems in which intrinsic growth rates are under selection to optimize a growth / predation risk trade-off, and growth rates are negatively related to the level of predation risk that species experience in natural habitats (Wissinger et al. 1999; Johansson 2000; Johansson and Suhling 2004). In the Libellula larvae, however, growth rates were only moderately related to activity level. Two species, L. luctuosa and L. incesta, that differed in growth rate in this study did not differ in activity level under any conditions (Fig. 2). This result combines with other recent work on odonates (McPeek et al. 2001; McPeek 2004) to suggest that differences in physiological traits (e.g., assimilation efficiency) may be the principal factors responsible for growth-rate differences between species. Nonetheless, the decline in both activity and growth rate in L. pulchella in the presence of Anax suggests that these measures are correlated, either through similar selection pressures or as the result of a functional relationship between activity and growth rate in this species.

Results from this study suggest that plasticity in growth rate has little effect on species distributions across habitat types with alternative top predators. Growth-rate plasticity was only observed in L. pulchella. Libellula pulchella decreased its growth rate in the presence of Anax (the predator with which it most commonly coexists) but not in the presence of bluegill (the predator which poses the greatest percapita risk). Because of limited exposure to bluegill, L. pulchella may not recognize the cues from bluegill as a threat. Plasticity in this species appears not to be related to the spatial variation it experiences in predation risk across habitats with alternative top predator types. Instead, the growth-rate plasticity exhibited may be related to the temporal variation in risk experienced within the habitats where it most commonly occurs: habitats where Anax are top predators. Variation in predation risk across ontogeny may favor plasticity in growth rates to take advantage of periods of low predation risk by increasing growth rate.

One pattern that emerged in this study was the ratio of thorax to body length in larvae. All three species had parallel responses to predators and developed larger thoraces rela- 
tive to the abdomen in the presence of bluegill than in the no predator treatment. Rapid swimming in larvae is achieved by the forcible expulsion of water from the rectal gill chamber (Corbet 1999) and thorax size has little effect on escape behavior in larvae. These observed differences may be an epiphenomenon associated with other growth or development effects induced in the presence of bluegill. However, there was no overall predator effect on growth rate and none of these species exhibited significant plasticity in growth rate between bluegill and no predator treatments, suggesting that this explanation is insufficient. In the adult stage, thorax mass is positively correlated with lifting force for flight (Schlider and Marden 2004) and thorax length is significantly positively correlated with thorax mass in adults (McCauley 2005). These results suggest an intriguing hypothesis: individuals may respond to perceived high levels of predation risk by increasing allocation to structures that improve flight performance and facilitate dispersal. It has been shown in other insects that exposure to a high-risk predator environment during development may favor increased investment into structures that improve dispersal performance (Weisser et al. 1999; Weisser 2001). It is not known, however, whether intraspecific variation in relative thorax size is related to dispersal or flight performance in these species.

Comparisons across only three species limit the ability to generalize these results. The history of these species' associations with habitats where we find them now is unknown and species may be optimizing alternative traits that were not measured. However, growth rate is an especially informative trait in understanding how trade-offs affect species distributions across habitat gradients, because it reflects an integration of multiple behavioral and physiological processes. The results of this study suggest that growth rate is related to species distributions and that there is a negative relationship between growth rate and the extent of coexistence with high-risk predators. Growth-rate plasticity appears to have little role in determining the ability of species to cope with spatial variation in predation risk but instead appears related to the level of temporal variability in predation risk that species experience across ontogeny. The relationship between species growth strategies and their habitat distributions provides insight into the forces structuring communities and the trade-offs species resolve in habitats with alternative top predator types.

\section{Acknowledgements}

The research presented in this paper was submitted to the Department of Ecology and Evolutionary Biology at the University of Michigan as part of a dissertation in partial fulfillment of the requirements for the degree of Doctor of Philosophy. Animals used in this experiment were cared for according to University of Michigan animal care guidelines. This research and manuscript were improved by comments from Earl Werner, Deborah Goldberg, Brian Hazlett, and Emily Silverman. Michael Fraker and two anonymous reviewers also provided comments that improved the manuscript. Stephan Schneider helped conduct the growth-rate experiment. The Museum of Zoology at the University of Michigan and Ronald Nussbaum provided access to the E.S.
George Reserve and Jeff Bolgos provided logistical support at the Reserve. This work was supported by funding from sources at the University of Michigan: an E.S. George Reserve Scholarship from the Museum of Zoology, a block grant from the Department of Ecology and Evolutionary Biology, and a Rackham Pre-doctoral Fellowship.

\section{References}

Arendt, J.D. 1997. Adaptive intrinsic growth rates: an integration across taxa. Q. Rev. Biol. 72: 149-177.

Benke, A.C. 1970. A method for comparing individual growth rates of aquatic insects with special reference to Odonata. Ecology, 51: 328-331.

Chivers, D.P., Wisenden, B.D., and Smith, R.J.F. 1996. Damselfly larvae learn to recognize predators from chemical cues in the predator's diet. Anim. Behav. 52: 315-320.

Clutton-Brock, T.H. 1988. Reproductive success: studies of individual variation in contrasting breeding systems. The University of Chicago Press, Chicago.

Corbet, P.S. 1999. Dragonflies: behavior and ecology of Odonata. Comstock Publishing Associates and Cornell University Press, Ithaca, N.Y.

Gotthard, K. 2001. Growth strategies of ectothermic animals in temperate environments. In Animal developmental ecology. Edited by D. Atkinson and M. Thorndyke. BIOS Scientific Publishers Ltd., Oxford, UK. pp. 287-304.

Honek, A. 1993. Intraspecific variation in body size and fecundity in insects: a general relationship. Oikos, 66: 483-492.

Johansson, F. 2000. The slow-fast life style characteristics in a suite of six species of odonate larvae. Freshw. Biol. 43: 149159.

Johansson, F., and Suhling, F. 2004. Behavior and growth of dragonfly larvae along a permanent to temporary water habitat gradient. Ecol. Entomol. 29: 196-202.

McCauley, S.J. 2005. Species distributions in anisopteran odonates: effects of local and regional processes. Ph.D. dissertation, University of Michigan, Ann Arbor.

McPeek, M.A. 2004. The growth/predation risk trade-off: so what is the mechanism? Am. Nat. 163: E88-E111.

McPeek, M.A., Grace, M., and Richardson, J.M.L. 2001. Physiological and behavioral responses to predators shape the growth/predation trade-off in damselflies. Ecology, 82: 15351545.

Roff, D.A. 1992. The evolution of life histories. Chapman and Hall, New York.

Schlichting, C.D., and Pigliucci, M. 1998. Phenotypic evolution: a reaction norm perspective. Sinauer Associates, Inc., Sunderland, Mass.

Schlider, R.J., and Marden, J.H. 2004. A hierarchical analysis of the scaling force and power production by dragonfly motors. J. Exp. Biol. 207: 767-776.

Sokolovska, N., Rowe, L., and Johansson, F. 2000. Fitness and body size in mature odonates. Ecol. Entomol. 25: 239-248.

SPSS Inc. 2002. SPSS ${ }^{\circledR}$. Version 11.5 [computer program]. SPSS Inc., Chicago.

Stearns, S.C. 1992. The evolution of life histories. Oxford University Press, New York.

Thornhill, R., and Alcock, J. 1983. The evolution of insect mating systems. Harvard University Press, Cambridge, Mass.

Weisser, W.W. 2001. The effects of predation on dispersal. In Dispersal. Edited by J. Clobert, E. Danchin, A.A. Dhondt, and J.D. Nichols. Oxford University Press, New York. pp. 180-190. 
Weisser, W.W., Braendle, C., and Minoretti, N. 1999. Predatorinduced morphological shift in the pea aphid. Proc. R. Soc. Lond. B Biol. Sci. 266: 1175-1181.

Wellborn, G., Skelly, D., and Werner, E. 1996. Mechanisms creating community structure across a freshwater habitat gradient. Annu. Rev. Ecol. Syst. 27: 337-363.
Werner, E.E., and Anholt, B.R. 1993. Ecological consequences of the trade-offs between growth and mortality rates mediated by foraging activity. Am. Nat. 142: 242-272.

Wissinger, S., Whiteman, H., Sparks, G., Rouse, G., and Brown, W. 1999. Foraging trade-offs along a predator-permanence gradient in subalpine wetlands. Ecology, 80: 2102-2116. 